\title{
The Debute of New Online Academician's Research Center; ARC Journal of Anesthesiology
}

\author{
Mohamad Said Maani Takrouri MB. ChB. FRCA (I) \\ Professor of Anesthesia \\ Alsafwah center Office No (1209) Prince Mandouh bin Abdelaziz street, Riyadh, KSA \\ mmtakrouri@aol.com
}

The introduction of online publishing opened a wide gate for anesthesiologist scholars to a wider communication and interchanges of scientific sharing and compares practice patterns and results. ARC as abbreviation sound (Ark) like in Nouah's Ark the ship he build to transfer his people and pairs of all animals to safety after major flood destined to cover the Earth ${ }^{[1]}$. The analogy between that ark and ARC journal the mentin of global in describing this journal.

This journal objective comes in time for all anesthesiologist of the world to come together. Obviously globalization made our planet Earth a one big village. And communications were developed to rush information in split of one hit of key board of personal communication apparatus.

Auther ascertains that publishing is getting exponential dimensions. Anesthesiologists as up-to-date health practitioners cannot stand behind. Their role opened great opportunities to revolutionize all medical sciences. ${ }^{[2]}$

Individual anesthesiologist should find it imperative that worldwide publicity of new science would call on all colleagues and students of anesthesia to have the benefits of this promising platform. By reading article or sending manuscript anesthesiologists will be included in the circle. The future prerequisites for promotion in the field or keeping current with literatures are not restricted to local hospital, national or regional society journals.

This as well goes in same direction of seeking helping hands from more conversed in research anesthesiologists to those who need such advanced contributors. Let us all experience this new project and discover this promising future.

Academicians' research center announced the launching of its international peer-review journal focusing on Academic research on anesthesiology, and its related sciences. The journal should hopefully principal forum serving the global intercontinental anesthesia community. It will adapt the rapid, open-access publication of All manuscripts content related to anesthesia, intensive care and pain medicine. The journal scope encompasses theoretical anesthesia modeling, simulations education, technology development, essays, clinical studies and its applications. Topics will include different fields in anesthesia, intensive care and pain medicine. Many features of the new journal will mirror those of the pioneering and highly successful publications, including rapid, online open-access publication and availability of free color figures, essays, review articles, and live reference links. The title is new and always new titles help to build emerging fields of study, enhance communications within existing research communities, and stimulate creative discourse at disciplinary interfaces.Editorial members believe that well-chosen, properly supported launches play a crucial role in the advancement of knowledge and global research among various anesthesiologists of the globe

It is essential for AJA to address strategic numerous topics like contribution to science, the scientific mission and vision; the likely market for subscriptions; the likely rate of submissions of papers of international levels of excellence; the fit with other journals produced by the world enthusiasm of a suitably experienced and qualified editorial team. The author believes that all the potentials and topics should meet the vision and mission of the journal. Now AJA is your journal, and in order to achieve success, the author joining the editorial board members to invite all the anesthesiologists to submit 
their articles to AJA. Author is aware that the initial step in promoting the AJA will be difficult but with the existing dedicated editorial board, AJA will reach equal standards with other existing anesthesia journals $[2,3]$.

\section{REFERENCES}

[1] Noah'Ark http://www.divinerevelations.info/noah/ last accessed Feb.4th 2016.

[2] Takrouri MS. Unfolding doctrines of modern anesthesia literature publication. Anesth Essays Res 2015;9:291-2

[3] Al-Saeed A. SJA is now on PubMed (Editorial) Saudi J Anaesth. 2010;4:45.

[4] Eldawlatly A (Editorial) PAFSA international journal - Anesthesia: Essays and Researches. Anesth Essays and Res 2010, 4(1):1 